\title{
ADENOMATOID TUMOR OF SUPRA-RENAL GLAND
}

\author{
NANCY T. DENICOL, FABRÍCIO R. LEMOS, WALTER J. KOFF \\ Section of Urology, Porto Alegre General Hospital, Federal University of Rio Grande do Sul (UFRGS), \\ Rio Grande do Sul, Brazil
}

\begin{abstract}
Adenomatoid tumors of adrenal gland are rare, asymptomatic neoplasias, with benign behavior, and usually are diagnosed incidentally.

We report a case of a voluminous adenomatoid tumor of left adrenal gland in a 42-year old man who sought evaluation because of renal colic due to left nephrolithiasis. During the investigation, a tumor localized in left adrenal gland was identified by ultrasonography (14.3 x $10.5 \times 19.0)$.

The patient underwent adrenalectomy and pyelolithotomy with histopathological and immunohistochemical diagnosis of adenomatoid tumor of adrenal gland, being the largest one described in the literature to the moment. The patient does not present any signs of recurring lesion after a 3-year follow-up.
\end{abstract}

Key words: adrenal glands; neoplams; adenomatoid tumors; nephrolithiasis

Int Braz J Urol. 2004; 30: 313-5

\section{INTRODUCTION}

Adenomatoid tumors of adrenal gland are rare, asymptomatic neoplasias, with benign behavior, and usually are diagnosed incidentally (1). Adenomatoid tumors appear more frequently in the genital system both in males and in females (2). The literature reports only 16 cases of adrenal adenomatoid tumors (3). In this work, we report one case of voluminous adenomatoid tumor affecting the left adrenal gland.

\section{CASE REPORT}

Caucasian, 42-year old man was referred due to presenting, during investigation of renal colic, a mass measuring $14.3 \times 10.5 \times 19.0 \mathrm{~cm}$ localized on left adrenal gland in ultrasonographic imaging. The patient had a previous history of systemic arterial hypertension with moderate tension levels since he was
28 years old, and elimination of urinary stones at the ages 32 and 39. On the physical examination, he presented blood pressure of $150 \times 100 \mathrm{mmHg}$ (using captopril) and a mass with firm consistency and indefinite limits on left hypochondrium. Abdominal computerized tomography demonstrate a tumor measuring $10.5 \times 9.9 \mathrm{~cm}$ localized on left adrenal gland, caudally displacing the ipsilateral kidney, showing peripheral impregnation by the contrast agent, presenting heterogeneous texture, with hypodense areas in its interior, possibly corresponding to necrotic areas, and a stone measuring $3.2 \times 2.7 \mathrm{~cm}$ in left renal pelvis corresponding to renal lithiasis. Dosing for urinary vanillylmandelic acid, cortisoluria, 17hydroxyprogesterone, hydro-epiandrosterone sulfate, androstenedione, aldosterone, follicle-stimulating hormone, luteinizing hormone, prolactin, total and free testosterone, thyrotrophin, thyroxine and cortisol (following $1 \mathrm{mg}$ of dexamethasone) were within the normal range. 
Adrenalectomy and pyelolithotomy were performed by open approach, with no intercurrences trans- or post-operatively. The adrenal gland weighted $535 \mathrm{~g}$ and upon sectioning it showed predominance of multicystic, yellowish and opaque tissue, with the tumor being predominantly solid. Histological examination with hematoxylin-eosin demonstrated mesothelial cells similar to epithelial lineage cells arranged as small tubules, cysts or string-shaped, with histological pattern compatible with adenomatoid tumor of adrenal gland (Figure-1). Immunohistochemical study by the immunoperoxidase technique using the markers AE1, AE3, vimentin, CEA and CD31, demonstrate that neoplastic cells were positive to AE1,
AE3 and vimentin (Figure-1), and negative to the other markers, confirming the diagnosis.

The patient has not shown signs of recurrent lesion after a 3-year follow-up.

\section{COMMENTS}

Adenomatoid tumors are benign neoplasias with mesothelial origin, with cases rarely reported in extra-genital sites (2). There are 8 cases describing adenomatoid tumor of adrenal gland, occurring mostly in males, involving more frequently the left adrenal gland (1). With the increasing use of imaging examinations for diagnostic of other pathologies, adrenal
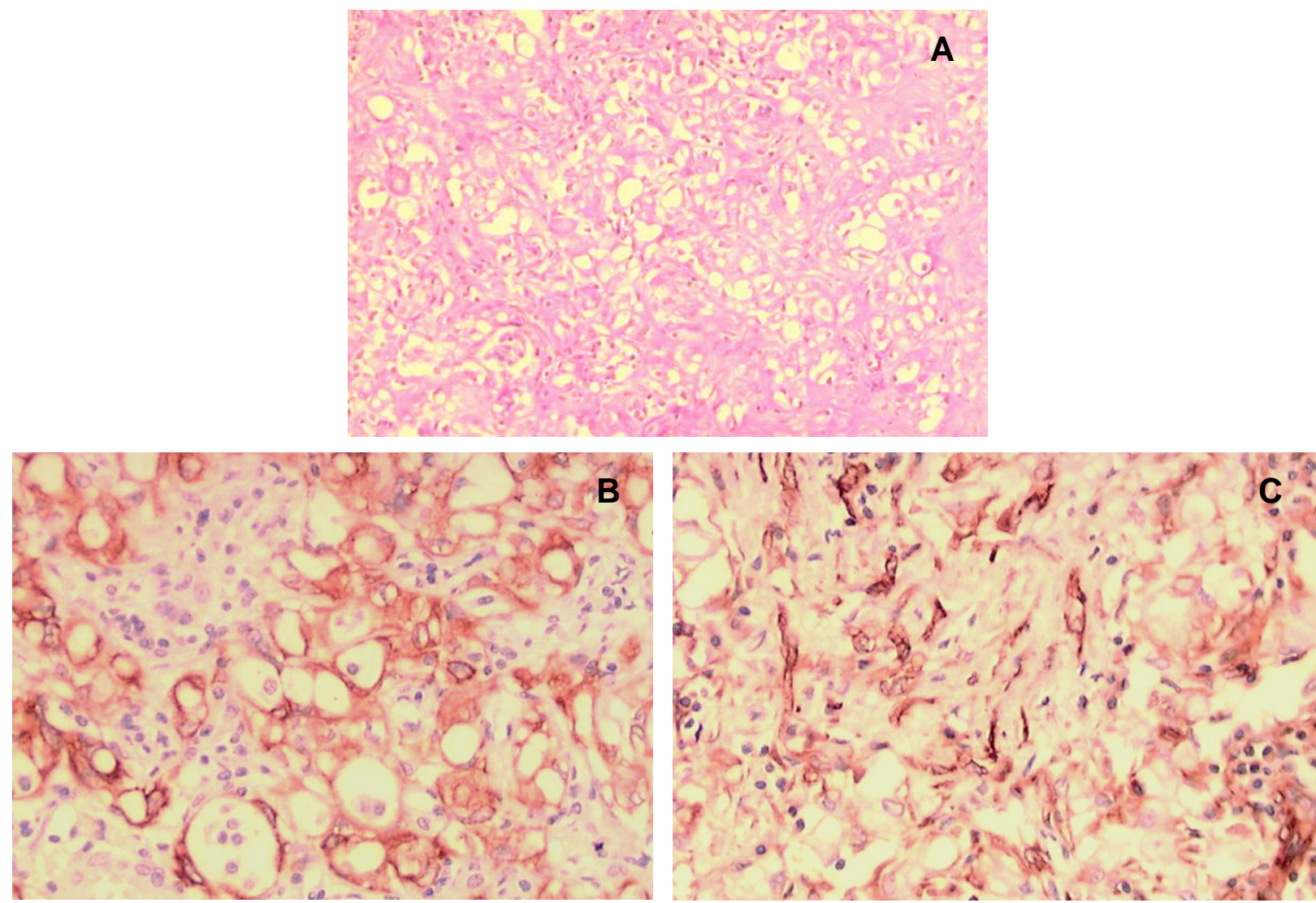

Figure 1 - Histological and immunohistochemical studies of the adenomatoid tumor of adrenal gland. A) Proliferation of mesothelial cells similar to epithelial lineage cells, arranged as small tubules, cysts, or string-shaped (HE, X80). B) Positivity for cytokeratins in epithelial-like cells. CEA negative. Positive to AE1 and AE3 (Imunolabeling, X200). C) Positivity for vimentin expressed in mesothelial cells (Imunolabeling, X200). 
tumors have been more diagnosed, usually in an incidental way. Apparently, there are no specific characteristics that enable us to radiologically distinguish adenomatoid tumors from other adrenal lesions (4). The differential diagnosis of an adrenal mass includes adrenal adenoma or carcinoma, myelolipoma, pheochromocytoma, cysts and metastatic neoplasias (1). There are no reports in the literature of lesion recurrence following complete surgical removal, and this treatment is definitive.

\section{REFERENCES}

1. Raaf HN, Grant LD, Santoscoy C, Levin HS, AbdulKarim FW: Adenomatoid tumor of the adrenal gland: a report of four new cases and a review of the literature. Mod Pathol. 1996; 9: 1046-51.

2. Glatz K, Wegmann W: Papillary adenomatoid tumour of the adrenal gland. Histopathology. 2000; 37: 3767.

3. Isotalo PA, Keeney GL, Sebo TJ, Riehle DL, Cheville JC: Adenomatoid tumor of the adrenal gland: a clinicopathologic study of five cases and review of the literature. Am J Surg Pathol. 2003; 27: 969-77.

4. Rodrigo Gasque C, Marti-Bonmati L, Dosda R, Gonzalez Martinez A: MR imaging of a case of adenomatoid tumor of the adrenal gland. Eur Radiol. 1999; 9: 552-4.
Received: May 26, 2004

Accepted after revision: July 30, 2004

Correspondence address:

Dr. Fabrício Rodrigues Lemos

Rua São Marcos 77 / 303

Porto Alegre, RS, 91420-550, Brazil

Tel.: + 5551 9812-4743

E-mail: fabriciorlemos@bol.com.br 